\title{
Factors Influencing Viscoelastic Properties of a Poly(Butylene Terephthalate) Reinforced With Short Glass Fibers
}

\author{
O. BEAUDOIN*, A. BERGERET**, J. C. QUANTIN, and A. CRESPY \\ ${ }^{*}$ Coflexip Stena Offshore, PID \\ 22 rue Jean Hure - BP 7 - 76580 Le Trait - France \\ Ecole des Mines d'Alès - Centre des Matériaux de Grande Diffusion \\ 6, avenue de Clavières - 30319 Alès Cedex - France
}

\begin{abstract}
Short glass fiber/poly(butylene terephthalate) composites with different glass fiber treatments were characterized within a temperature range from $-150^{\circ} \mathrm{C}$ to $+150^{\circ} \mathrm{C}$ by dynamic tests in torsion and tensile modes. Untreated fibers or fibers coated by silane coupling agents associated or not with sticking agents were used. It was observed that the magnitude of $\beta$ and $\alpha$ relaxations depends stronghy on the microstructural parameters of such composites: fiber content, degree of crystallinity of the matrix, fiber length distribution, level of adhesion.
\end{abstract}

\section{INTRODUCTION}

$\mathrm{T}$ The two past decades have witnessed the emergence of engineering fiber-reinforced polymers such as poly(butylene terephthalate) (PBT)/glass fiber composites. Improved mechanical properties of these composites require an efficient load transfer between the fiber and the matrix and therefore a good interfacial bonding. The problem of understanding the complex nature of the interphase region has attracted considerable attention from both academic and industrial researchers. A wide range of analytical methods are available to investigate the interfacial region in the composite. These techniques include Fourier transform infrared spectroscopy (1-4), nuclear magnetic spectroscopy $(1,3)$, mass spectrometry $(1,5)$ and differential scanning calorimetry $(1,3)$. Moreover several micromechanical tests on single fibers have been developed to evaluate fiber/matrix interfacial adhesion such as microindentation (6) and pull-out $(7,8)$ methods. Nevertheless, these techniques do not really allow a global approach of the composite behavior because they are not sensitive to the process. Dynamic mechanical analysis seemed to be more suitable to characterize the interfacial region, including processing effects.

Several authors have studied the dynamic mechanical behavior of unidirectional composites, most of these studies dealing with amorphous matrices

".Corresponding author: Email: Anne.Bengeret@ema.fr
(1, 9-12). Recently, some dynamic mechanical investigations were carried out on semicrystalline matrices reinforced by short glass fibers (13-15). Dynamic mechanical data for this kind of composite have been shown to depend on the following parameters: (i) the fiber degradation that should occur during the process and determines the fiber length distribution (16), (ii) the nature of the surface treatment of the fiber $(17,18)$, (iii) the degree of crystallinity of the matrix (19) and (iv) the fiber content (20). These microstructural parameters are usually interconnected, and only parameters (ii) and (iv) are controllable before processing.

\section{EXPERIMENTAI PROCEDURE}

\subsection{Materials}

Poly(butylene terephthalate) (PBT) was obtained from DuPont de Nemours Company under the trade name Crastin ${ }^{\circledR}$. Its weight-average molar weight $\bar{M}_{w}$, determined by a light scattering method, is 19,100 Daltons. The carboxyl end-group content is about 45 equivalent $/ 10^{6} \mathrm{~g}$ and was measured by titration using Pohl's method (21). The reactivity of these carboxyl end groups is known to be higher than that of the hydroxyl end groups (22). E-glass fibers were provided by Vetrotex Saint Gobain Company (Chambery, France) with three surface treatments including amino- or epoxysilane, either with or without sticking agents (SA) based on epoxy resins. The weight fraction of sizing on glass fibers was estimated by a burning method. The effective filler fractions were measured by burning 
samples at $625^{\circ} \mathrm{C}$ during $4 \mathrm{~h}$ according to the ISO 1172 standard. Results are reported in Table 1.

\subsection{Sample Preparation}

Poly(butylene terephthalate) composite specimens were reinforced by $15 \mathrm{wt} \%$ of glass fibers. A corotating twin screw extruder (Clextral BC21) was used to mix the glass fibers and the polymer matrix. The pellets of compounds were then injection molded at $270^{\circ} \mathrm{C}$ (Sandretto Serie Otto A.T.) and cooled at $80^{\circ} \mathrm{C}$ to obtain dumbbells according to ISO 527-2 type 1A standard. The weight fraction of sizing on glass fibers is estimated at about 0.1 to $0.9 \%$ (Table 2).

\subsection{Experimental Techniques}

\subsubsection{Microstructural Characterization}

Fiber length distribution. The fibers recovered after burning the $\mathrm{PBT}$ matrix at $625^{\circ} \mathrm{C}$ during $4 \mathrm{~h}$ were studied by optical microscopy (Leica) and measured by TV camera and image analysis (Optimas). A specific semi-automatic technique was used (23-25). It is based on an individual analysis of each fiber to obtain the size distribution. For each sample, a population of 800 to 1000 fibers was evaluated and characterized statistically. We obtain various kinds of size distribution representations:

- the number size distribution represented by the number-average length $\overline{L_{n}}$ according to the following equation:

$$
\bar{L}_{n}=\frac{\sum_{i} P_{i} L_{i}}{\sum_{i} P_{i}}
$$

where $P_{i}$ is a weight factor associated to the fiber of length $L_{i}$

- the weight size distribution represented by the weight-average length $\overline{L_{w}}$ as follows:

$$
\bar{L}_{w}=\frac{\sum_{i} P_{i} L_{i}^{2}}{\sum_{i} P_{t} L_{i}}
$$

- the dispersity coefficient $D$ representing the spreading of the length fiber distribution:

$$
D=\frac{\bar{L}_{w}-\bar{L}_{n}}{\bar{L}_{n}}
$$

Table 1. Characteristics of Poly(Butylene TerephthalateVGlass Fiber Composites.

\begin{tabular}{lc}
\hline Sample & Effective Fiber Fraction (wt\%) \\
\hline PBT & - \\
UT & $17.85 \pm 0.02$ \\
AS & $15.03 \pm 0.01$ \\
AS-SA & $15.05 \pm 0.02$ \\
ES-SA & $15.16 \pm 0.02$ \\
\hline
\end{tabular}

Matrix crystallinity. The melting behavior of all samples and therefore the crystallinity ratio was studied by differential scanning calorimetry using a DSC 92 from Setaram. Scans were carried out from room temperature to $300^{\circ} \mathrm{C}$ at a heating rate of $20^{\circ} \mathrm{C} / \mathrm{min}$. The crystal weight fraction is theoretically determined from the relation $X_{c}=\frac{\Delta H_{f}}{\Delta H_{f}^{0}}$, where $\Delta H_{f}$ is the melting enthalpy of the composite and $\Delta H_{f}^{\circ}$ the melting enthalpy of perfectly crystalline PBT. Nevertheless, it was impossible to get a reliable value of $\Delta H_{f}^{O}$ and it was decided to quantify the crystallinity of the composite by $\Delta H_{f}$ which is directly correlated to the crystal weight fraction. For each composite the value of $\Delta H_{f}$ was calculated, taking account of the real weight fraction of PBT.

\subsubsection{Dynamic Mechanical Characterization}

Two kinds of dynamic mechanical analyzers were used under isochronal conditions to study $\alpha$ and $\beta$ mechanical relaxations associated respectively to the glass and subglass transitions. The temperature range was set between $-150^{\circ} \mathrm{C}$ and $+150^{\circ} \mathrm{C}$. A viscoelasticimeter VA815 Metravib R.D.S. was used in tensile mode for recording the dynamic mechanical spectra versus temperature at a frequency of $5 \mathrm{~Hz}$ on parallelepipedic samples $\left(25 \times 4 \times 2 \mathrm{~mm}^{3}\right)$. The real part $\left(E^{\prime}\right)$ of the dynamic modulus and the loss factor $\left(\tan \delta_{\mathrm{E}}\right)$ were measured. A torsion pendulum SMD2000 Metravib R.D.S. was used for recording the shear modulus, $G^{\prime}$ and the loss factor, $\tan \delta_{G}$ versus temperature at frequencies of 0.02 and $2 \mathrm{~Hz}$ on smaller specimens $\left(20 \times 4 \times 1.5 \mathrm{~mm}^{3}\right)$.

\section{RESULTS AND DISCUSSION}

\subsection{Microstrectural Characterization}

\subsubsection{Fiber Length Distribution}

During the extrusion and injection processes of fiber-reinforced molded parts, the distributions of fiber length and fiber orientation are governed by various factors. These include the original length and concentration of fibers, the surface treatment of fibers and the processing conditions $(26,27)$. Most authors agree that the stresses exerted upon fibers by the molten material and the dies are the main cause of fiber length reduction. Therefore, when the fiber/ matrix interface adhesion is optimized, these stresses are higher and a more important length reduction can be observed. Moreover, it was pointed out that the

Table 2. Characteristics of Glass Fibers.

\begin{tabular}{lcc}
\hline Sample & Sizing Constituents & Fraction of Sizing (wt\%) \\
\hline UT & untreated & - \\
AS & aminosilane & $0.07 \pm 0.02$ \\
AS-SA & aminosilane + sticking agents & $0.77 \pm 0.01$ \\
ES-SA & epoxysilane + sticking agents & $0.88 \pm 0.01$ \\
\hline
\end{tabular}




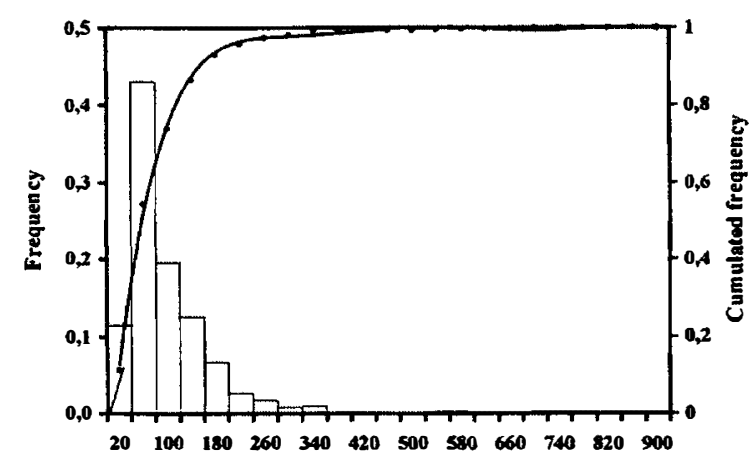

(a)

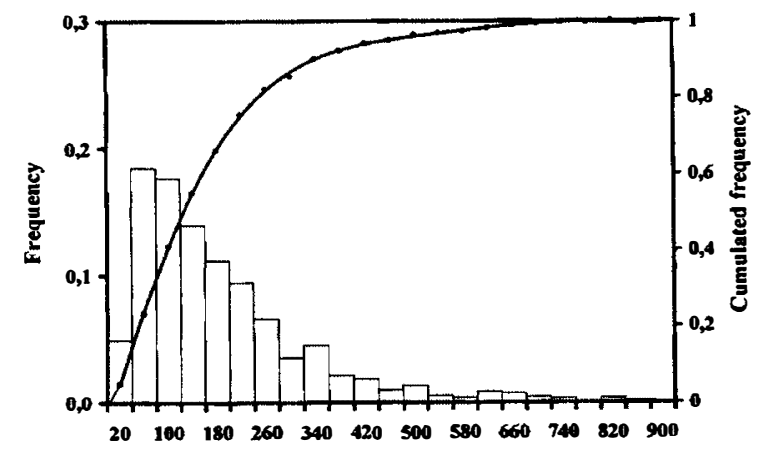

(b)

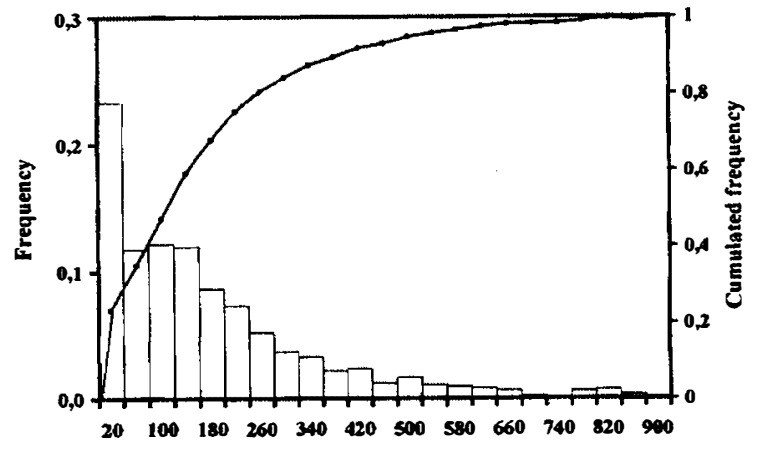

(c)

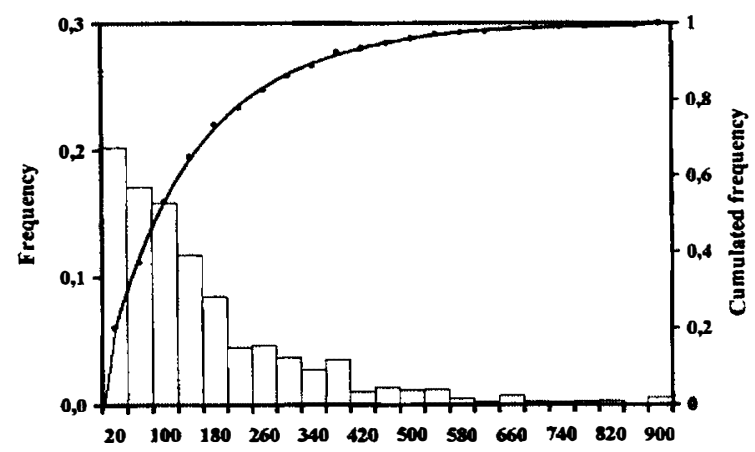

(d)

Fig. 1. Number size distribution of the different surface treated fibers: (a) untreated, (b) AS treated, (c) AS-SA treated and (d) ES-SA treated.

mechanical properties such as the tensile strength and the flexural stiffness of any material depend on the fiber length and orientation distributions $(28,29)$.

Figure 1 shows the number length distributions of fibers obtained for the four composites studied. All the results are summarized in Table 3.

The number-average length $\bar{L}_{n}$ and weight-average length $\bar{L}_{w}$ and dispersity coefficient $D$ strongly depend on the presence and the nature of the surface treatment:

(i) A comparison between composites reinforced by untreated fibers (UT) and fibers treated by silane coupling agent alone (AS) shows an increase of the number-average length $\bar{L}_{n}$ (respectively weight-average length $\bar{L}_{w}$ ) without modification of the dispersity coefficient $D$ in presence of surface treatment. These results are attributed to the initial poorer dry integrity of the untreated fibers before composite elaboration. The dry integrity is defined as the ability of the fibers to adhere together in the bundle, and the higher the

Table 3. Fiber Length Data After Injection Molding.

\begin{tabular}{lccc}
\hline Sample & $\overline{L_{n}}(\mu \mathrm{m})$ & $\overline{L_{w}}(\mu \mathrm{m})$ & $D$ \\
\hline UT & 96.6 & 152.2 & 0.57 \\
AS & 183.5 & 291.9 & 0.59 \\
AS-SA & 176.0 & 335.2 & 0.91 \\
ES-SA & 161.3 & 312.2 & 0.94 \\
\hline
\end{tabular}

integrity, the lower the degradation in the solid conveying zones of the processing machines.

(ii) With a sticking agent in the sizing composition, an increase of the length distribution spreading was observed without modification of the number-average length (AS and AS-SA). The sticking agent seems to favor the spreading of the distribution.

(iii) The nature of the silane coupling agent did not significantly modify either average number length or the dispersity coefficient (AS-SA and ES-SA).

\subsubsection{Matrix Crystallinity Ratio}

The results showed an influence of the fiber surface treatment on the crystallinity ratio. Data from Table 4 show no variations or a slight decrease in the degree of crystallinity without shift of the melting temperature for the composite reinforced by untreated fibers, and an increase in the degree of crystallinity without shift of the melting temperature for composites reinforced by coated fibers.

Table 4. DSC Results for PBT and Its Composites.

\begin{tabular}{lcc}
\hline Sample & $\mathbf{T}_{\boldsymbol{m}}\left({ }^{\circ} \mathrm{C}\right)$ & Melting Enthalpy $(\mathrm{J} / \mathbf{g})$ \\
\hline PBT & $236.5 \pm 1.4$ & $-51.6 \pm 1.2$ \\
UT & $237.6 \pm 0.9$ & $-49.2 \pm 2.2$ \\
AS & $238.0 \pm 0.9$ & $-57.1 \pm 1.8$ \\
AS-SA & $236.6 \pm 0.4$ & $-57.1 \pm 1.8$ \\
ES-SA & $236.5 \pm 0.6$ & $-59.4 \pm 3.1$ \\
\hline
\end{tabular}


These results can be explained by two antagonistic factors-the matrix substitution by glass fibers and the nucleating effect of the coated glass fibers. Concerning the first effect, the thermal diffusivity being higher for glass than for melt polymer (30), the matrix substitution by glass fibers should increase the matrix cooling rate during the molding process, owing to improved thermal conductivity. This should induce a decrease in the crystallinity ratio $(18,31)$. Concerning the second factor, the nucleating effect of coated glass fibers $(13,32)$ should create a more extended transcrystalline layer. The matrix crystallinity might depend also upon the fiber length and orientation distributions. Indeed, these parameters influence the distance between the fibers and may change the matrix cooling rate and the crystallinity degree. Nevertheless, these parameters have not been measured and therefore their influence has not been taken into account.

\subsection{Dyaamic Mechanical Characterization}

\subsubsection{Relaxations of the Pure Matrix}

Numerous investigations have been carried out on the dynamic mechanical properties of PET $(19,33-38)$, but just a few on the viscoelastic behavior of PBT (13, 39). PBT exhibits at least two mechanical loss peaks in the temperature range $-150^{\circ} \mathrm{C}$ to $+150^{\circ} \mathrm{C}$. The $\beta$ relaxations, which occur at about $-85^{\circ} \mathrm{C}$ at $5 \mathrm{~Hz}$, is associated to motions of parts of the macromolecular chains. This relaxation characteristic polymethylene terephthalate polymers such as PET or PBT has been
Table 5. Results Obtained for $\beta$ and $\alpha$ Mechanical Relaxations of PBT/Glass Fiber Composites.

\begin{tabular}{lcccc}
\hline Sample & $\mathbf{T}_{\boldsymbol{\beta}}\left({ }^{\circ} \mathbf{C}\right)$ & $\tan \boldsymbol{\delta}_{\boldsymbol{\beta}}$ & $\mathbf{T}_{\alpha}\left({ }^{\circ} \mathbf{C}\right)$ & $\tan \boldsymbol{\delta}_{\boldsymbol{\alpha}}$ \\
\hline PBT & $-85.2 \pm 0.4$ & 0.044 & $61.4 \pm 0.9$ & 0.114 \\
UT & $-85.6 \pm 0.2$ & 0.038 & $60.1 \pm 0.3$ & 0.078 \\
AS & $-84.8 \pm 0.4$ & 0.034 & $57.9 \pm 0.2$ & 0.063 \\
AS-SA & $-88.6 \pm 0.2$ & 0.031 & $60.4 \pm 0.1$ & 0.058 \\
ES-SA & $-85.9 \pm 0.3$ & 0.031 & $58.3 \pm 0.2$ & 0.058 \\
\hline
\end{tabular}

attributed to the superposition of two or

three kinds of local motions of the $-\mathrm{CH}_{2}$ - and $-{ }_{\mathrm{O}}^{-\mathrm{C}-\mathrm{O}-}$ groups. The second peak located at $61^{\circ} \mathrm{C}$ at $5 \mathrm{~Hz}$ is related to the main $\alpha$ relaxation that is associated to the collective motions of the glass transition. All the results are summarized in Table 5 and Fig. 2.

\subsubsection{Relaxations of the Matrix in Presence of Glass Fibers: Influence of the Surface Treatment}

Figures 3 and 4 show the real part $\left(\mathrm{E}^{\prime}\right)$ of the dynamic mechanical modulus and the loss tangent (tan $\delta_{\mathrm{E}}$ ) curves recorded at $5 \mathrm{~Hz}$ for composites near $\beta$ and $\alpha$ transitions.

The presence of glass fibers induces a decrease in the $\tan \delta$ maximum for both relaxations (Table 5). That has been already observed (13). Additional differences on the $\tan \delta$ peak magnitude were obtained according to the surface treatment:

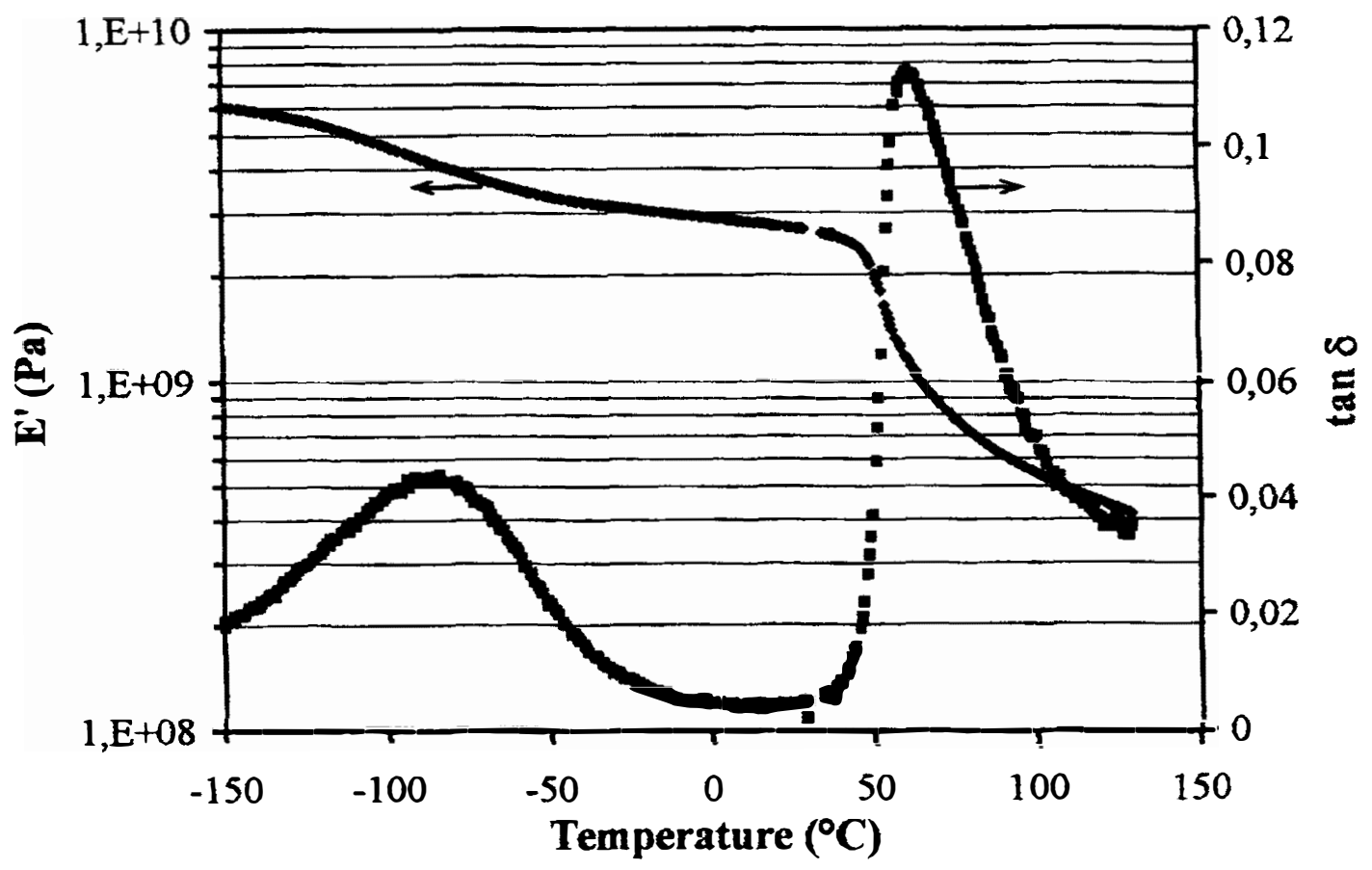

Fig. 2. Plots of $E^{\prime}$ and $\tan \delta_{E}$ versus temperature at $5 \mathrm{~Hz}$ for PBT (tensile mode). 


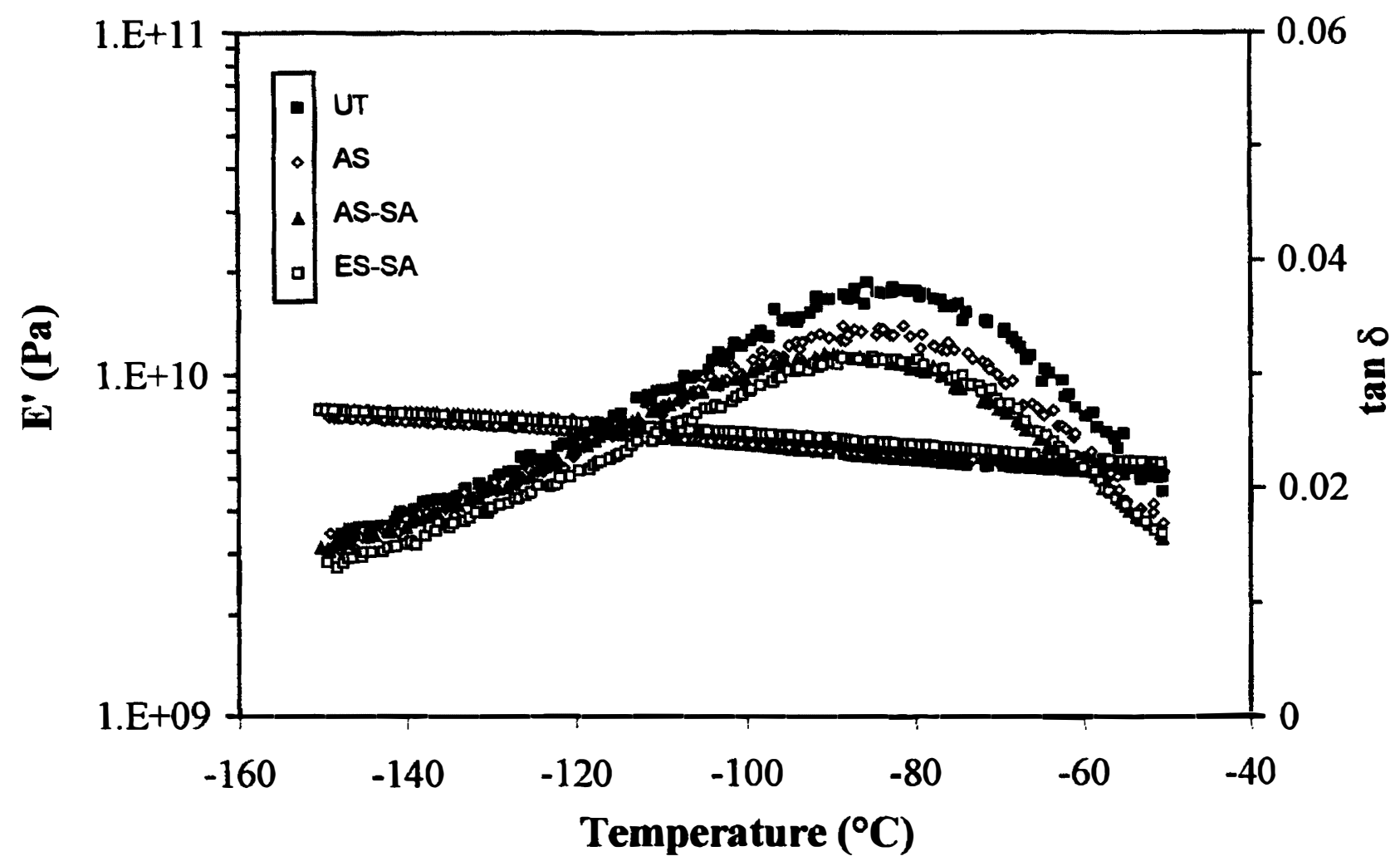

Fig. 3. Plots of $E^{\prime}$ and tan $\delta_{E}$ versus temperature at $5 \mathrm{~Hz}$ near $\beta$ relaxation for composites reinforced by 15 wt\% of fibers with different surface treatments (tensile mode).

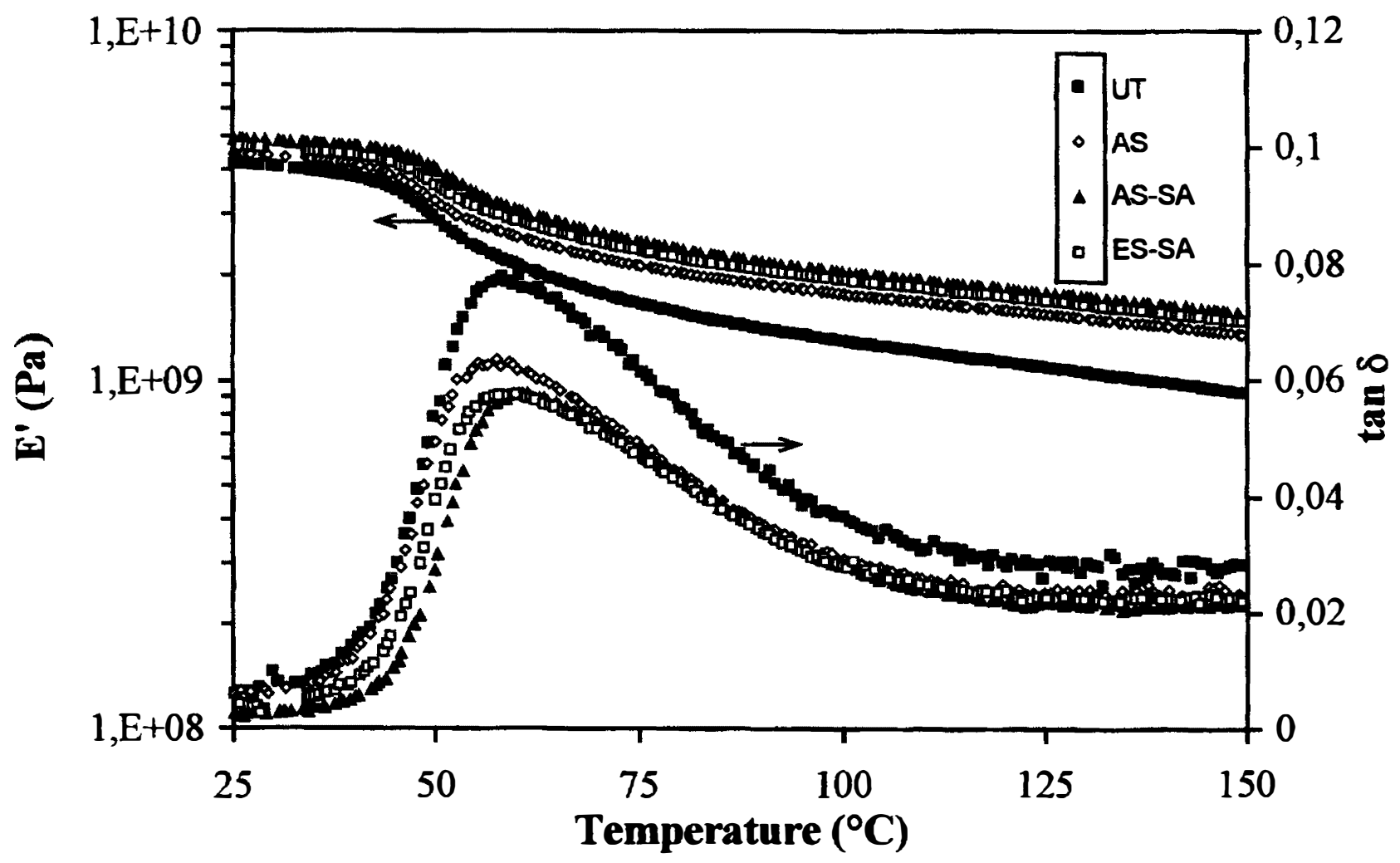

Fig. 4. Plots of $E^{\prime}$ and $\tan \delta_{E}$ versus temperature at $5 \mathrm{~Hz}$ near $\alpha$ relaxation for composites reinforced by 15 wt\% of fibers with different surface treatments (tensile mode). 


$$
\begin{aligned}
& \tan \delta_{\beta_{A S-S A}} \approx \tan \delta_{\beta_{E S-S A}}<\tan \delta_{\beta_{A S}}<\tan \delta_{\beta_{U T}} \\
& \tan \delta_{\alpha_{A S-S A}} \approx \tan \delta_{\alpha_{E S-S A}}<\tan \delta_{\alpha_{A S}}<\tan \delta_{\alpha_{U T}}
\end{aligned}
$$

Three parameters may be taken into account to explain these results: (i) the influence of the fiber length distribution, (ii) the influence of the nature of the surface treatment on fibers, which modifies the nature of the bonds between the PBT macromolecular chains and the glass surface, (iii) the influence of the degree of crystallinity.

It has been shown in a previous study (40) that the magnitude of the $\beta$ relaxation is mainly controlled by the first parameter (i). Indeed, in this temperature range, only local motions of $-\mathrm{CH}_{2}-$ and $-\mathrm{C}-\mathrm{O}-$ groups can

occur, which should not be significantly disrupted by variations of the crystallinity ratio or by the presence of a surface treatment. Nevertheless the interactions between the components of the sizing and the PBT chains exist. In the case of the AS-SA surface treatment, a covalent amide bond is likely to be created between carboxyl end groups of the PBT chains and the amine units of the aminosilane coupling agent. In the case of the ES-SA surface treatment, a covalent bond should be created between carboxyl end groups of the PBT chains and the epoxy units of the epoxysilane coupling agent.
On the other hand, the magnitude of the $\alpha$ relaxation is sensitive to parameters (i), (ii) and (iii). In this temperature range, correlated motions of molecular chains are observed. Physical and/or chemical links between the sizing components and the PBT chains, on the one hand, and the degree of crystallinity, on the other hand, may hinder greatly these molecular motions. The stronger these links, the lower the magnitude of the mechanical relaxation, for quite similar crystallinities and fiber lengths. In our case, the larger height of $\tan \delta$ peak for untreated fibers is attributed to the weakness of physical links, fiber lengths and crystallinity. The lower magnitude of $\tan \delta$ peak for AS, AS-SA and ES-SA samples is mainly due to the increase in the number of chemical and/or physical crosslinkings while the crystallinity ratio and the fiber length are similar. Thus the presence of a sticking agent in the glass fiber sizing seems to reduce molecular mobility of the PBT matrix without clear influence of the nature of the silane coupling agent.

In order to distinguish the silane coupling agents and their effect on dymamic mechanical behavior (samples AS-SA and ES-SA), the same composites were characterized at lower frequencies $(0.02$ and $2 \mathrm{~Hz})$ with a torsion pendulum in the temperature domain of the $\alpha$ relaxation. No clear differences were observed at $2 \mathrm{~Hz}$ (Fig. 5). On the other hand, for a lower frequency of $0.02 \mathrm{~Hz}$ a higher $\tan \delta$ peak was measured in the case of an epoxysilane coupling agent (Fig. 6):

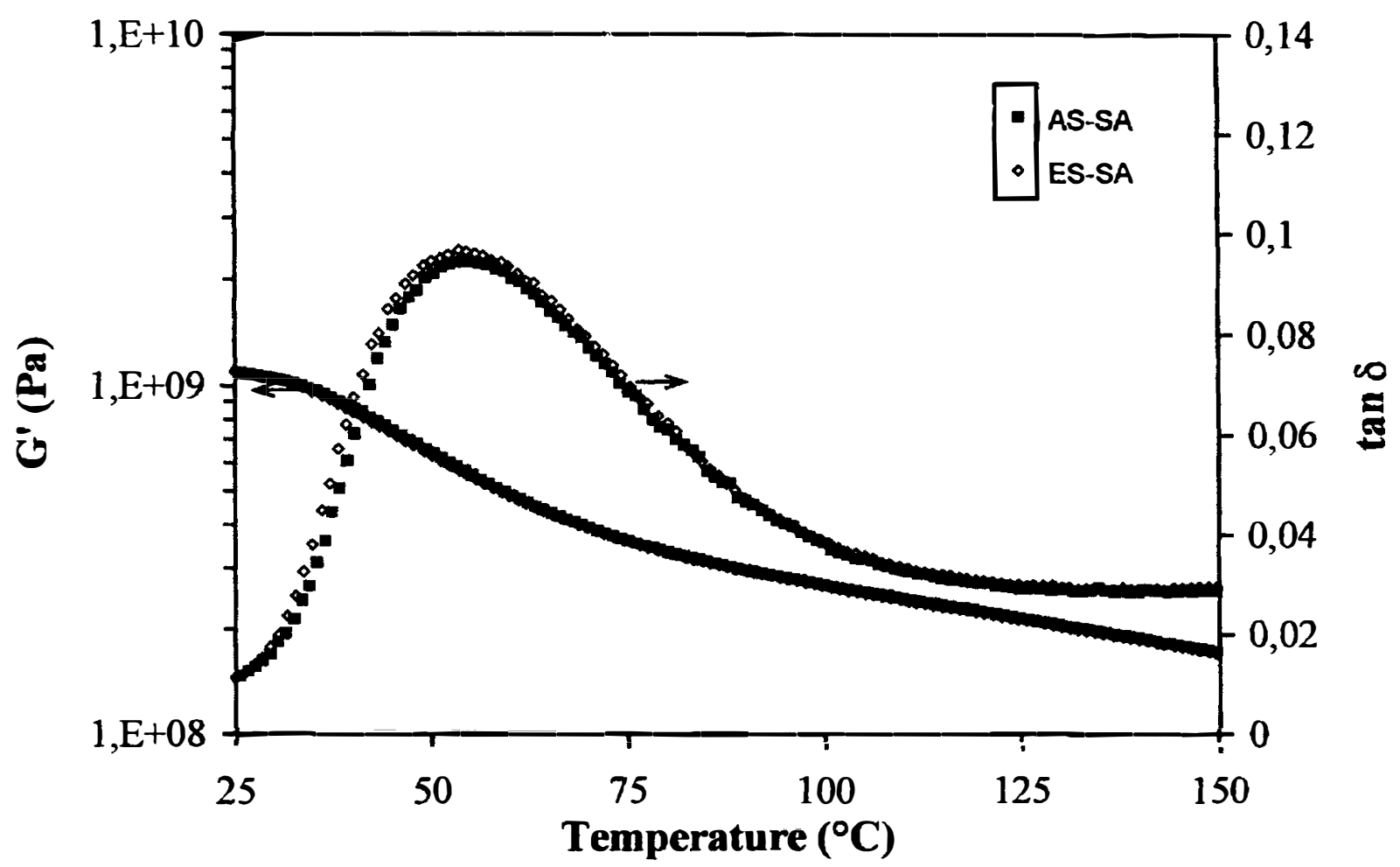

Fig. 5. Plots of $G^{\prime}$ and $\tan \delta_{G}$ versus temperature at $2 \mathrm{~Hz}$ near a relacation for composites reinforced by 15 wt\% of fibers with different surface treatments (torsion mode). 


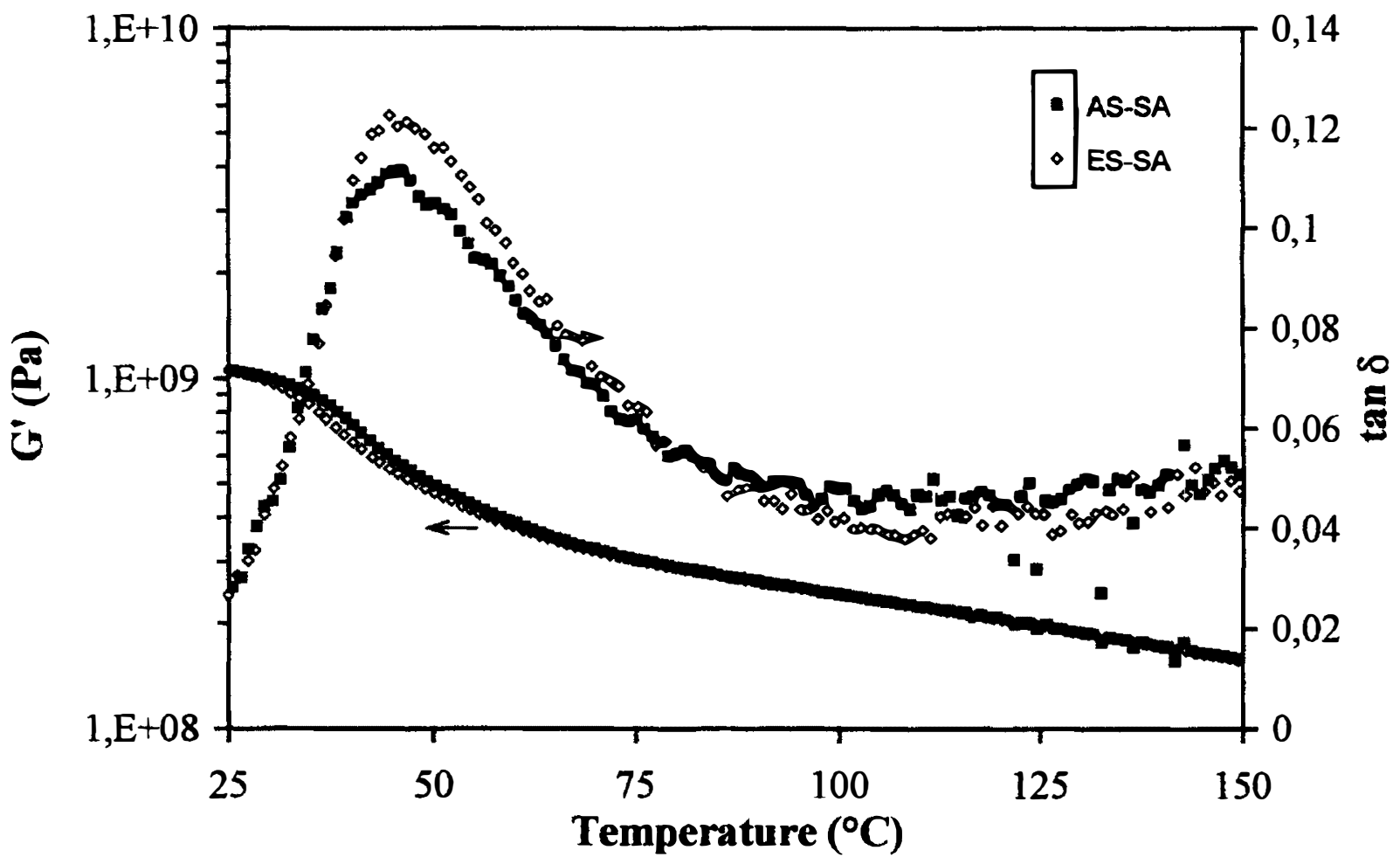

Fig. 6. Plots of $G^{\prime}$ and $\tan \delta_{G}$ versus temperature at $0.02 \mathrm{~Hz}$ near $\alpha$ relaxation for composites reinforced by 15 wt\% of fibers with different surface treatments (torsion mode).

$$
\tan \delta_{A S-S A}<\tan \delta_{E S-S A}
$$

These results are summarized on Table 6. Such differences might be attributed to the stronger reduction of molecular mobility of fibers in the presence of an aminosilane coupling agent. The aminosilane-based coating is clearly more efficient than the epoxysilanebased one for the fiber/matrix mechanical coupling.

\section{CONCLUSIONS}

The aim of this work was to examine the relationships between microstructural parameters of a PBT reinforced with short glass fibers and its viscoelastic behavior. The microstructural characterization has given evidence of a strong contribution of the sizing components on the final fiber length distribution. Indeed, the silane coupling agent seems to favor an increase in the number-average length without modification of the dispersity coefficient, while the sticking

Table 6. Results Obtained for a Mechanical Relaxation in the Case of PBT/Glass Fiber Composites: Influence of the Silane Coupling Agent Nature.

\begin{tabular}{lccc}
\hline Sample & Frequency $(\mathbf{H z})$ & $\left.\mathbf{T}_{\boldsymbol{\alpha}} \boldsymbol{}^{\circ} \mathbf{C}\right)$ & $\tan \boldsymbol{\delta}_{\boldsymbol{\alpha}}$ \\
\hline AS-SA & 2 & 55.5 & 0.095 \\
& 0.02 & 46.3 & 0.111 \\
ES-SA & 2 & 54.2 & 0.097 \\
& 0.02 & 44.7 & 0.122 \\
\hline
\end{tabular}

agent seems to favor an increase of the dispersity coefficient without modification of the number-average length. Moreover, the introduction of coated fibers in the matrix increases the matrix crystallinity ratio. Two antagonistic parameters might explain the results: the matrix substitution by glass fibers, which seems to improve thermal conductivity, and the nucleating effect of the coated fibers. The dynamic mechanical study of the $\beta$ and $\alpha$ relaxation has shown a decrease of the $\beta$ and $\alpha$ relaxations in the presence of fibers. The $\beta$ relaxation characteristics did not depend on the fiber length, the crystallinity ratio and the presence of additional physical and/or chemical crosslinkings between the carboxyl end groups of the PBT chains and the silane coupling agent. On the contrary, the $\alpha$ relaxation characteristics gave evidence of a molecular motion decrease when the glass fibers are coated. A low-frequency analysis in torsion mode allowed to distinguish the better efficiency of an aminosilane-based coating as compared to an epoxysilane-based one.

\section{REFERTNCES}

1. J. L. Thomason, Composites, 26, 7, 487-498 (1995).

2. Y. T. Liao, Polym Compos., 10, 424 (1989).

3. K. P. Hoh, H. Ishida, and J. L. Koenig, Polym Compos., 9, 151 (1988).

4. S. R Culler, H. Ishida, and J. L. Koenig, Polym. Compos., 7, 231 (1986).

5. T. E. Gentle, R. G. Schmidt, B. M. Naasz, A. Gellman, and T. M. Gentle, J. Adhesion Sci. Technol., 6, 2, 307316 (1992). 
6. H. F. Wu, D. W. Dwight, and N. T. Huff, Compos. Sci. and Technol, 57, 975-983 (1997).

7. E. J. Berger and Y. Eckstein, Adhesive Joints, Plenum Publishing Corporation, 51-65 (1984).

8. C. Y. Yue and M. Y. Quek, J. Mater. Sci., 28, 2487-2490 (1994).

9. P. S. Chua, Polym. Compos., 8, 308 (1987).

10. J. Chauchard, B. Chabert, P. Jeanne, and G. Nemoz, Journal de Chimie Physique, 84, 2, 1-4 (1987).

11. K. E. Reed, Polym. Compos., 1, 44 (1980).

12. V. F. Babich and Y. S. Lipatov, J. Appl. Polym. Sci, 24, 53-62 (1982).

13. M. Joshi, S. N. Maiti, and A. Misra, Polymer, 35, 17, 3679 (1994).

14. A. Haddout, M. Elghorba, and G. Villoutreix, Matériaux et Techniques, 8-10, 39 (1996).

15. C. Gauthier, L. Caramaro, and J. Chauchard, C. R. Acad. Sci Paris, T313, II, 891-894 (1991).

16. P. S. Theocaris, The Mesophase Concept in Composites, Springer-Verlag (1987).

17. F. Ulrych, M. Sova, J. Vokrouhlecky, and B. Turcic, Polym Compos., 14, 229 (1993).

18. S. Bonfield-Cahuzac, PhD Thesis, Ecole des Mines, Paris, France (1994).

19. C. Gauthier, J. F. Chailan, and J. Chauchard, Makromol. Chem, 194, 1421 (1993).

20. A. Bergeret and N. Alberola, Polymer, 37, 13, 2759-2765 (1996)

21. H. A. Pohl, Analytical Chemistry, 26, 1614-1616 (1954).

22. C. C. Huang and F. C. Chang, Polymer, 38, 9, 21652141 (1997).

23. L. Averous, PhD Thesis, Ecole des Mines, Paris, France (1995).
24. L. Averous, J. C. Quantin, D. Lafon, and A. Crespy, Polym. Eng. Sci, 37, 2, 329 (1997).

25. O. Beaudoin, PhD Thesis, Univ. Montpellier, France (1998).

26. K. Ramani, D. Bank, and N. Kraemer, Polym. Compos., 16, 258 (1995).

27. D. Dospisil, J. Kubat, M. Plezek, and P. Saha, Intern. Polym. Processing, 8, 4, 303-309 (1994).

28. M. Xia, H. Hamada, and Z. Maekawa, Intern. Polym. Processing, X, 1, 74-81 (1995).

29. S.Y. Su and B. Lauke, Compos. Sci. Tech, 56, 11791190 (1996).

30. C. Rauwendaal, Polymer Extrusion, Hanser (1990).

31. J. Cinquin, B. Chabert, J. Chauchard, E. Morel, and J. P. Trotignon, Composites, 21, 2, 141 (1990).

32. L. M. Parrinello, Tappi Joumal, 85 (1991).

33. K. H. Hlers and H. Breuer, J. Coll. Sci, 18, 1-31 (1963).

34. C. D. Armeniades and E. Baer, J. Polym. Sci., Part A2, 8 , 1345-1369 (1971).

35. J. H. Dumbleton and T. Murayama, Kolloid Zeitschrift and Zeitschrift für Polymere, 220, 1, 41-48 (1967).

36. I. I. Perepechko, V. A. Danilov, V. V. Nizhegorodov, N. P. Bessonova, and Z. V. Konyukhova, Polym. Sci, 35, 2, 193-196 (1993).

37. A. B. Thompson and D. W. Woods, Transactions of the Faraday Society, 52, 1383-1397 (1956).

38. T. A. Ezquerra, F. J. Balta-Calleja, and H. G. Zachmann, Acta Polymer, 44, 18-24 (1993).

39. G. Farrow, J. Mc Intosh, and I. M. Ward, Research Department of the Imperial Chemical Industries Limited, Fibres Division, Harrogate, England, 147-158 (1960).

40. O. Beaudoin, A. Bergeret, J. C. Quantin, and A. Crespy, Composite Interfaces, 5, 6, 543-559 (1998) 